DOI: $10.26730 / 1999-4125-2018-3-93-100$

УДК 547.992.2:662.73

ПЕРЕРАБОТКА БУРЫХ УГЛЕЙ В ЭФФЕКТИВНЫЕ СОРБЕНТЫ ДЛЯ РЕШЕНИЯ ЗАДАЧ ОХРАНЫ ОКРУЖАЮЩЕЙ СРЕДЫ И ПОВЫШЕНИЯ КАЧЕСТВА ЖИЗНИ

\title{
PROCESSING OF BROWN COALS INTO EFFECTIVE SORBENTS FOR SOLVING PROBLEMS OF ENVIRONMENTAL PROTECTION AND IMPROVING THE QUALITY OF LIFE
}

\author{
Козлов Алексей Петрович ${ }^{1,2}$, \\ кандидат хим. наук, доцент, \\ e-mail: KozlovAP@,KuzSTU.ru \\ Alexey P. Kozlov ${ }^{1,2}$, \\ Candidate of Chemical Science, associate professor, \\ Зыков Игорь Юрьевич ${ }^{2}$, \\ кандидат физ.-мат. наук, научный сотрудник, \\ e-mail: zyak.kot@mail.ru \\ Igor Yu. Zykov', \\ Candidate of Math and Physics Science, researcher, \\ Дудникова Юлия Николаевна ${ }^{2}$, \\ кандидат хим. наук, научный сотрудник, \\ e-mail: dudnikova.yuliya80@,mail.ru \\ Yuliya N. Dudnikova ${ }^{2}$, \\ Candidate of Chemical Science, researcher, \\ Цветков Вячеслав Эдуардович ${ }^{2}$ \\ аспирант, e-mail: tsvetkofve@,gmail.com \\ Vyacheslav E. Tsvetkov ${ }^{2}$ \\ postgraduate, \\ Фёдорова Наталья Ивановна ${ }^{2}$ \\ кандидат хим. наук, ведущий научный сотрудник, e-mail: FedorovaNI@iccms.sbras.ru \\ Nataliya I. Fedorova ${ }^{2}$, \\ Candidate of Chemical Science, leading researcher, \\ Исмагилов Зинфер Ришатович, ${ }^{1,2}$ \\ член-корреспондент РАН, заведующий кафедрой, e-mail: Zinferl@mail.ru \\ Zinfer R. Ismagilov ${ }^{1,2}$, \\ Corresponding member of the Russian Academy of Sciences, head of the Department

\footnotetext{
${ }^{1}$ Кузбасский государственный технический университет имени Т.Ф. Горбачева, 650000, Россия, г. Кемерово, ул. Весенняя, 28.

${ }^{1}$ T.F. Gorbachev Kuzbass State Technical University, 28 Vesennyaya street, Kemerovo, 650000, Russian Federation

${ }^{2}$ Федеральный исследовательский центр угля и углехимии СО РАН (Институт углехимии и химического материаловедения), 650000, Россия, г. Кемерово, Советский пр., 18

${ }^{2}$ Federal Research Center of Coal and Coal Chemistry SB RAS (Institute of coal chemistry and materials science), 18 Sovetskiy av., Kemerovo, 650000, Russian Federation
}

Аннотация: В работе показана возможность переработки бурых углей Кузбасса в эффективные сорбенты на примере бурого угля Тисульского месторождения. Щелочная активация бурого угля позволяет получать углеродные сорбенты с высокими характеристиками пористости. Гомогенизацию угле- 
щчелочной смеси осуществляли методом пропитки щелочным раствором с последующей сушкой. Массовое соотношение КОН уголь составляло: 0.25 г/2; 0.5 г/2; 1 г/2 и 2 г/2. Показано положительное влияние количества гидроксида калия на характеристики сорбентов получивиихся при щелочной активации. С ростом соотношения КОН/уголь статическая сорбция йода, фенола и метиленового голубого из водньх растворов возрастает вследствие развития пористой структуры сорбента. Характеристики пористости углеродных сорбентов исследованы на анализаторе ASAP-2020 и электронном микроскопе JEOL JSM - 6390 LV. Пористая структура в сорбентах, полученных из бурого угля Тисульского месторождения методом щзелочной активачии, представлена микропорами. Наибольиий прирост текстурных и сорбционных характеристик наблюдается при использовании массового соотношения КОН/уголь 0.5г/2.

Ключевые слова: углеродные сорбенты, бурый уголь, щеелочная активация, пористая структура, адсорбиия

Abstract: The paper shows the possibility for processing brown coals of Kuzbass into effective carbon sorbents by the example of brown coal of the Tisulskoye field. The alkaline activation of brown coals provides an opportunity to obtain carbon sorbents with high porosity characteristics. Homogenization of the coal-alkaline mixture was carried out by impregnation with an alkaline solution with subsequent drying. The KOH/coal mass ratios were $0.25 \mathrm{~g} / \mathrm{g} ; 0.5 \mathrm{~g} / \mathrm{g} ; \mathrm{lg} / \mathrm{g} ; 2 \mathrm{~g} / \mathrm{g}$. The positive effect of potassium hydroxide on characteristics of sorbents obtained with alkaline activation is shown. The sorption of iodine, phenol and methylene blue increases with an increase in the $\mathrm{KOH} / \mathrm{coal}$ ratio due to the development of the sorbent porous structure. The porosity characteristics of carbon sorbents are investigated with the ASAP-2020 analyzer and JEOL JSM-6390 LV electron microscope. The porous structure of sorbents obtained from the brown coal of the Tisulsky field by the alkaline activation method is mainly re-presented by micropores. The highest increase in the porous structure is observed when KOH/coal mass ratio $0.5 \mathrm{~g} / \mathrm{g}$ was used.

Key words: carbon sorbents, brown coal, alkaline activation, porous structure, adsorption

Экологическая проблема, связанная с загрязнением водных ресурсов планеты, в настоящее время не теряет свою актуальность. Высокие темпы развития тяжёлой и лёгкой промышленности, автотранспорта влекут за собой возрастающую нагрузку на поверхностные воды [1-3]. Качество некоторых природных источников воды является неприемлемым для использования их не только для пищевых целей, но и технических нужд. В водоёмах могут присутствовать, в количествах значительно превышающих ПДК, опасные органические вещества, тяжёлые металлы, радионуклиды - такая вода является некачественной и непременно нуждается в очистке. Использование углеродных сорбентов, как основного материала для сорбционной очистки на этапе комплексной технологии очистки воды, является актуальным [4].

Существуют различные схемы получения углеродных сорбентов, которые включают подготовку исходного сырья, карбонизацию и активацию карбонизата газом (водяным паром и/или углекислым газом). Кроме того, помимо газов активации, используются и различные химические реагенты на стадиях карбонизации и подготовки сырья. В качестве сырья для производства углеродных сорбентов используются: разнообразное растительное сырьё [5-6]. (разные сорта древесины, скорлупа различных орехов, остатки стеблей и оболочек семян), продукты переработки углеродсодержащих веществ (пластмасс, резины, нефти), уголь [7]. Значения удельной поверхности углеродных сорбентов, в том числе полученных из бурых углей по традиционным схемам, составляет не более $600 \mathrm{~m}^{2} /$ г [8].
В работах [9-10] показано, что щелочная активация (термолиз в присутствии щёлочи) углей различной природы приводит к формированию развитой пористой структуры получаемых углеродных сорбентов. На углях низких стадий метоморфизма возможно получение сорбентов с удельной поверх-

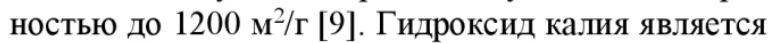
наиболее эффективным реагентом в реакции щелочной активации углей [11]. В литературе также известно, что возможно получение высокопористых сорбентов из антрацитов, значения удельной поверхности в данном случаи может доходить до $3000 \mathrm{M}^{2} / \Gamma$, однако данный результат достигается только при использовании очень высокого массового соотношения КОН/уголь 4:1 г/г [12]. Использование большого количества щёлочи порождает ряд экономических проблем, связанных со стоимость активирующей щёлочи, и экологических проблем, связанных с необходимость удаления большого количества щёлочи из продукта и последующей её дезактивацией.

В качестве исходного сырья для получения углеродных сорбентов можно использовать низкометаморфизованные бурые угли [13-14] - относительно дешевое и доступное сырье. Высокий выход летучих и наличие большого количества кислородсодержащих групп делает данный уголь эффективным при щелочной активации. Эти особенности бурых углей позволяют использовать небольшие количества щёлочи при активации, тем самым повысив экологичность технологии получения сорбентов.

Таким образом, методом щелочной активации 
Вестник Кузбасского государственного технического университета. 2018. № 3, с.93-100 Козлов А.П., Зыков И.Ю., Дудникова Ю.Н., Цветков В.Э., Фёдорова Н.И., Исмагилов З.Р....

Таблица 1. Характеристика угля Тисульского месторождения

Table 1. The characteristic of the coal of the Tisulskoye field

\begin{tabular}{|c|c|c|c|c|c|c|c|}
\hline \multicolumn{2}{|c|}{ Технический анализ, \% } & \multicolumn{3}{c|}{$\begin{array}{c}\text { Элементный состав, } \\
\text { \% на } d a f\end{array}$} & \multicolumn{2}{c|}{$\begin{array}{c}\text { Атомное } \\
\text { отношение }\end{array}$} \\
\hline$W^{a}$ & $A^{d}$ & $V^{\text {daf }}$ & $\mathrm{C}$ & $\mathrm{H}$ & $(\mathrm{O}+\mathrm{N}+\mathrm{S})$ & $\mathrm{H} / \mathrm{C}$ & $\mathrm{O} / \mathrm{C}$ \\
\hline 11.5 & 10.4 & 46.7 & 70.4 & 4.4 & 25.2 & 0.75 & 0.27 \\
\hline
\end{tabular}

мөжно получать углерөдные сорбенты с высөкнми значениями характеристик пористой структуры для решения экологических задач по извлечению растворённых примесей из воды.

\section{Характеристики угля}

В работе использовали бурый уголь разреза Кайчакский Тисульского месторождения, расположенного в Кемеровской области. Из исходного угля последовательным измельчением и квартованием была приготовлена проба угля с крупностью частиц 0.2-0.5 мм и высушена на воздухе. Для аналитических исследований из неё приготовили аналитическую пробу с размером частиц менее 0.2 мм.
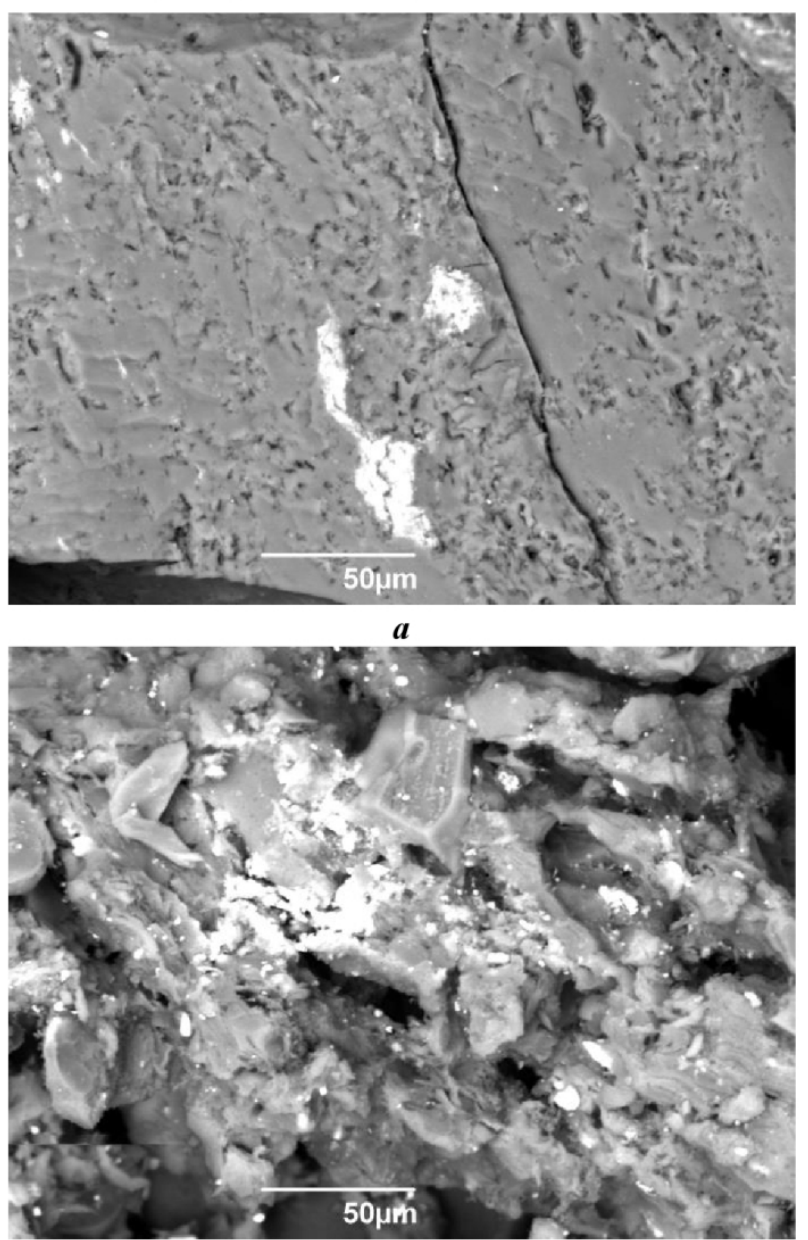

c
Исследования характернспнк проведены в соответствии со стандартами ИСО 602-74, 562-74 (технический анализ) и ИСО 625-75 (элементный состав).

Исследованные характеристики угля Тисульского месторождения представлены в таблице 1.

По результатам технического анализа видно, что исходный уголь характеризуется достаточно высокой зольностью $(10.4 \%)$ и влажностью $(11.5 \%)$, большим содержанием гетероатомов (25.2\% на daf). Анализ на содержание серы в органической массе угля проводили согласно ГОСТ 8606-93.Сера в органической массе угля обнаружена только в следовых количествах.

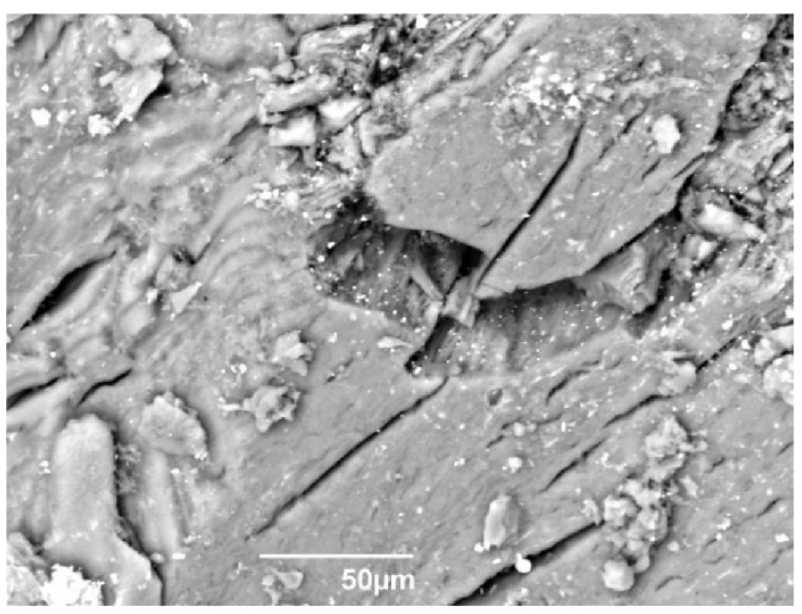

b

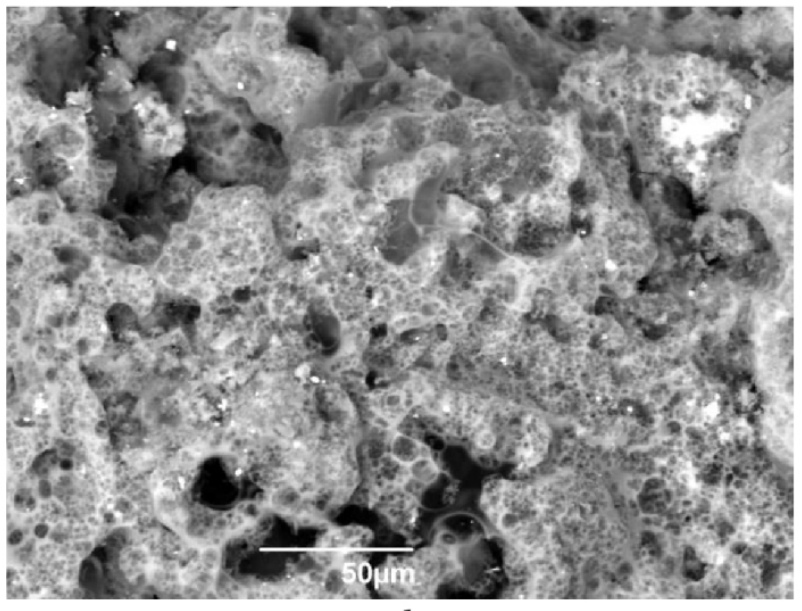

$d$

Рис. 1. Микрофотографии поверхности углеродных сорбентов, полученных из бурого угля Тисульского месторождения при различных массовых соотношения $\mathrm{KOH}$ уголь $\left(R_{K о H}\right)$ $\left(a-\right.$ без шёлочи; $b-R_{K O H}=0.52 / 2, c-R_{K O H}=12 / 2 ; d-R_{K O H}=2$ 2/2)

Fig. 1 Microphotographs of the surface of carbon sorbents obtained from the coal of the Tisulskoye field at different $\mathrm{KOH} /$ coal mass ratios $\left(R_{\mathrm{KOH}}\right)$

( $a$ - without alkali; $b-R_{\mathrm{KOH}}=0.5 \mathrm{~g} / \mathrm{g}, c-R_{\mathrm{KOH}}=1 \mathrm{~g} / \mathrm{g} ; d-R_{\mathrm{KOH}}=2 \mathrm{~g} / \mathrm{g}$ ) 


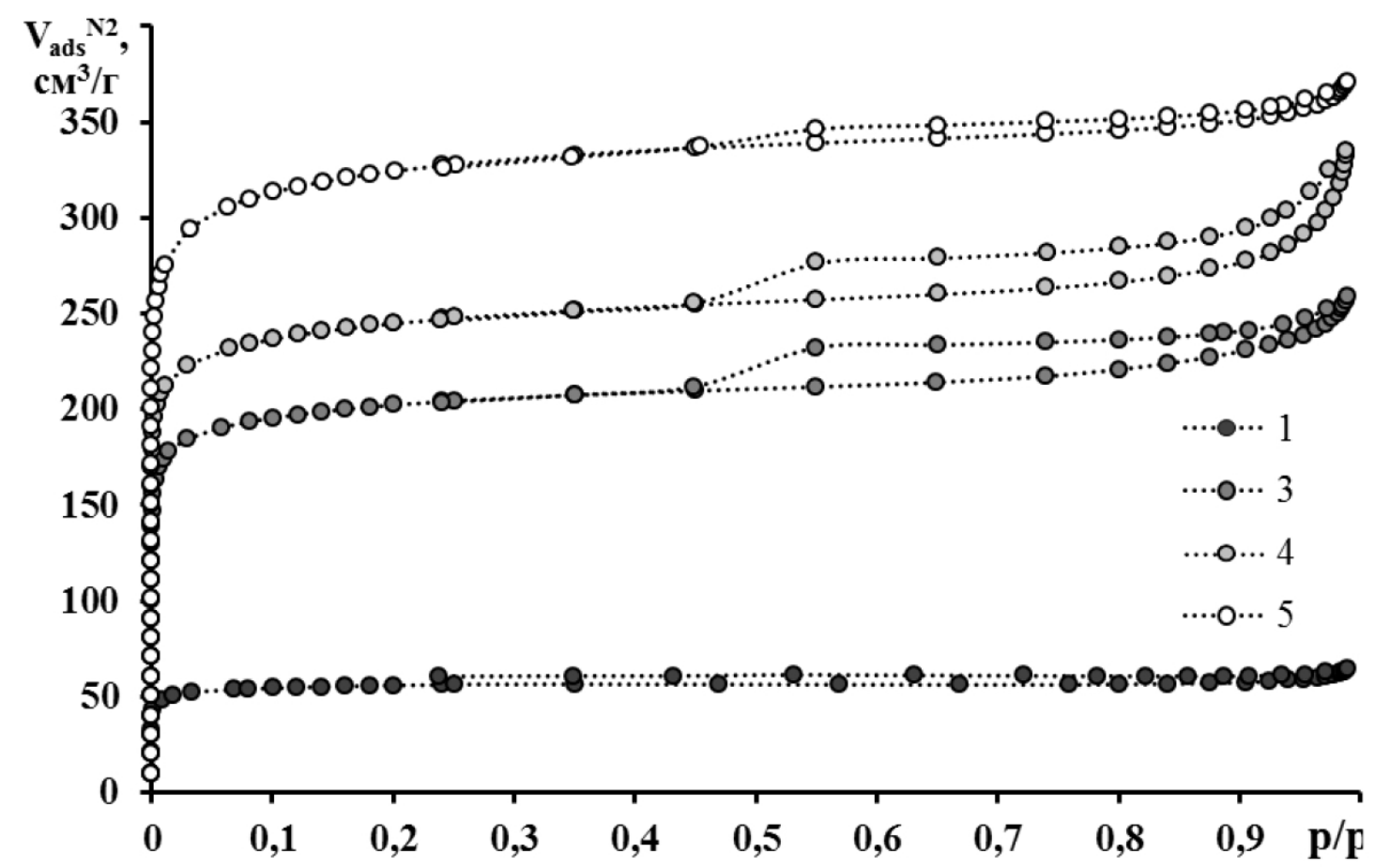

Рис. 2. Изотермы адсобции-десорбции азота при 77К для углеродных сорбентов, полученных из угля Тисульского месторождения при различных массовых соотношениях КОН/уголь $\left(R_{\text {Кон }}\right)$ $\left(1-\right.$ без щееллочи; $3-R_{\mathrm{KOH}}=0.5$ 2/2; $4-R_{\mathrm{KOH}}=1$ 2/2; $5-R_{\mathrm{KOH}}=2$ 2/2)

Fig. 2. Nitrogen adsorption-desorption isotherms at $77 \mathrm{~K}$ for carbon sorbents obtained from the coal of Tisulskoye field at different $\mathrm{KOH} /$ coal mass ratios $\left(R_{\mathrm{KOH}}\right)$

$\left(1-\right.$ without alkali; $\left.3-R_{\mathrm{KOH}}=0.5 \mathrm{~g} / \mathrm{g} ; 4-R_{\mathrm{KOH}}=1 \mathrm{~g} / \mathrm{g} ; 5-R_{\mathrm{KOH}}=2 \mathrm{~g} / \mathrm{g}\right)$

\section{Получение сорбентов}

Получение сорбентов проводили методом щелочной активации (термолиза угля в присутствии гидроксида калия) по методике, описанной в [9]. Использовали уголь с размером частиц 0.2-0.5 мм, который пропитывался в течение 24 часов раствором гидроксида калия. Далее смесь сушили в сушильном шкафу при $105 \pm 5^{\circ} \mathrm{C}$ до полного высыхания. Таким образом получали гомогенную смесь гидроксида калия и угля. Количество щелочи брали таким образом, чтобы массовое соотношение КОН/уголь ( $\left.\mathrm{R}_{\mathrm{KOH}}\right)$ было равным - 0.25 г/г; 0.5 г/г; 1 г/г; 2 г/г. Нагрев углещелочной смеси проводили в закрытых тиглях в муфельной печи. Процесс нагрева состоял из двух этапов: увеличение температуры со скоростью $7-9^{\circ} \mathrm{C} / \mathrm{Mин} \mathrm{до} 800^{\circ} \mathrm{C}$ и изотермическое выдерживание в течение 1 часа. Далее тигли вынимали и помещали в эксикатор для охлаждения. Спекшиеся карбонизованные остатки измельчали до крупности частиц $<1$ мм, затем последовательно отмывали от щелочи дистиллированной водой, 0.1 н раствором соляной кислоты и далее дистиллированной водой до нейтральной реакции среды. Промытые сорбенты высушивали в сушильном шкафу при $105 \pm 5^{\circ} \mathrm{C}$ до постоянной массы. Полученные сорбенты представляют собой неоднородный порошок, состоящий из частиц раз- личных размеров, поэтому для проведения исследований текстурных и сорбционных характеристик подготовили сорбенты крупностью 0.2-0.5 мм.

\section{Пористая структура}

При помощи электронного микроскопа JEOL JSM-6390LV были получены микрофотографии участков поверхности полученных в работе сорбентов (Рис. 1).

На фотографиях видна эволюция поверхности при увеличении количества щёлочи при активации. У карбонизата, полученного без щёлочи (Рис. 2а), поверхность практически ровная с незначительными углублениями. При щелочной активации гидроксидом калия поверхность сорбентов начинает усложняться. Заметные трещины начинают появляться при $\mathrm{R}_{\mathrm{KOH}}=0.5$ г/г (Рис. 2b), при увеличении $\mathrm{R}_{\mathrm{KOH}}$ до 1 г/г происходит образование крупных трещин с губчатой структурой стенок (Рис. $2 \mathrm{c}$ ), а при $\mathrm{R}_{\mathrm{KOH}}=2$ г/г практически вся поверхность сорбента губчатая с круглыми отверстиями пор различного радиуса (Рис. 2d).

Исследование пористой структуры сорбентов (удельная поверхность $-S_{B E T}, \mathbf{M}^{2} / \Gamma$, общий объем пор $-\mathrm{V}_{\Sigma}, \mathrm{cm}^{3} / \Gamma$, объем мезопор $-\mathrm{V}_{\text {mе }}, \mathrm{cm}^{3} / \Gamma$ и микропор $-\mathrm{V}_{\mathrm{mi}}, \mathrm{cm}^{3} /$ г) проводили на анализаторе ASAP2020. Характеристики пористой структуры сорбентов определяли по изотермам низкотемпературной 
Таблица 2. Характеристики сорбентов, полученных из угля Тисульского месторождения при различных массовых соотношениях КОН/уголь $\left(\mathrm{R}_{\mathrm{KOH}}\right)$

Table 2. Characteristics of the sorbents obtained from the coal of the Tisulskoye field at different $\mathrm{KOH} / \mathrm{coal}$ mass ratios $\left(\mathrm{R}_{\mathrm{KOH}}\right)$

\begin{tabular}{|c|c|c|c|c|c|c|c|c|}
\hline № & $\mathrm{R}_{0, \Gamma / \Gamma}$ & $S_{B E T,} \mathrm{M}^{2} / \Gamma$ & $\mathrm{V}_{\Sigma}, \mathrm{cm}^{3} / \Gamma$ & $\mathrm{V}_{\mathrm{mi}}, \mathrm{cm}^{3} / \Gamma$ & $\mathrm{V}_{\mathrm{me}}, \mathrm{cm}^{3} / \Gamma$ & $\mathrm{A}_{\mathrm{I}}, \mathrm{M \Gamma} / \Gamma$ & $\mathrm{A}_{\mathrm{P}}, \mathrm{M \Gamma} / \Gamma$ & $\mathrm{A}_{\mathrm{M}}, \mathrm{M \Gamma} / \Gamma$ \\
\hline 1 & без щёлочи & 215 & 0.10 & 0.070 & 0.006 & 71 & 9 & 9 \\
\hline 2 & 0.25 & 265 & 0.10 & 0.090 & 0.006 & 174 & 40 & 21 \\
\hline 3 & 0.5 & 760 & 0.39 & 0.250 & 0.120 & 450 & 125 & 30 \\
\hline 4 & 1 & 910 & 0.49 & 0.295 & 0.195 & 510 & 180 & 90 \\
\hline 5 & 2 & 1210 & 0.56 & 0.400 & 0.100 & 1040 & 250 & 205 \\
\hline
\end{tabular}

(77 К) адсорбции азота в области равновесных относительных давлений паров азота от $10^{-3}$ до $0.995 \mathrm{p} / \mathrm{p}_{0}$.

Характеристики пористой структуры сорбентов рассчитывали на основании анализа изотерм адсорбции-десорбции азота при 77 К, измеренных на анализаторе удельной поверхности ASAP-2020 (Рис. 2.). Перед проведением измерений для полного удаления сорбированных примесей образцы сорбентов вакуумировали при $200^{\circ} \mathrm{C}$ в течение 12 часов и остаточном давлении $5 \cdot 10^{-3}$ мм. рт. ст.

Для определения удельной поверхности сорбентов использовали модель Brunauer-EmmettTeller (БЭТ), для расчета объёма микропор применяли t-plot метод с использованием уравнения Harkins-Jura, объём мезопор рассчитывали методом Barrett-Joyner-Halenda (BJH). Данные методы позволяют рассчитать характеристики пористой структуры углеродных сорбентов, полученных на основе нативных углей [15].

\section{Статическая сорбция}

Измерение адсорбционной активности углеродных сорбентов осуществляли по статической сорбции из водных растворов фенола (АР, мг/г), йода $\left(\mathrm{A}_{\mathrm{I}}, \mathrm{Mг} / \mathrm{r}\right)$ и метиленового голубого $\left(\mathrm{A}_{\mathrm{M}}, \mathrm{Mг} / \Gamma\right)$. Измерение сорбционной активности по йоду проводили методом титрования йода, оставшегося после сорбции, тиосульфатом натрия (ГОСТ 621774). Измерение сорбционной активности по метиленовому голубому проводили согласно ГОСТ 4453-74, измеряя концентрацию красителя, оставшегося после сорбции в растворе на спектрофотометре в видимой области спектра. Измерение сорбционной активности по отношению к фенолу в водном растворе проводили на спектрофотометре с использованием индикатора.

Результаты измерений адсорбционной активности и характеристики пористости сорбентов представлены в таблице 2.

\section{Обсуждение результатов}

В таблице 2 приведены характеристики пористой структуры сорбентов ( $S_{B E T}-$ удельная поверхность, $\mathrm{V}_{\Sigma}$ - общий объём пор, $\mathrm{V}_{\mathrm{mi}}$ - объём микропор, $\mathrm{V}_{\mathrm{me}}$ - объём мезопор), а также их сорбционная активность из водных растворов по йоду $\left(\mathrm{A}_{\mathrm{I}}\right)$, фенолу $\left(\mathrm{A}_{\mathrm{P}}\right)$ и метиленовому голубому $\left(\mathrm{A}_{\mathrm{M}}\right)$. Анализ полученных данных показывает, что увеличение количества вводимого гидроксида калия при щелочной активации бурого угля Тисульского месторождения приводит к увеличению всех текстурных и адсорбционных характеристик полученных сорбентов.

Сорбент, полученный без добавления щёлочи, отличается малыми значениями характеристик пористости, однако уже обладает удельной поверхностью $S_{B E T}=215 \mathrm{~m}^{2} / \Gamma$. Тем не менее сорбция из всех исследованных растворов практически отсутствует, что говорит о низкой активности сорбента без щелочной активации.

При добавлении небольшого количества КОН $\left(\mathrm{R}_{\mathrm{KOH}}=0.25 \Gamma / \Gamma\right)$ рост удельной поверхности практически не происходит (увеличение на 23\%), адсорбционные характеристики увеличиваются более чем в 2 раза по сравнению с сорбентом, полученным без добавления гидроксида калия.

Если использовать соотношение $\mathrm{R}_{\mathrm{KOH}}=0.5 \mathrm{r} / \mathrm{\Gamma}$ происходит значительный прирост как удельной поверхности и объёма пор, так и сорбционных характеристик (Рис. 3). Наименьший прирост наблюдается для сорбции метиленового голубого из водного раствора. Линейные зависимости адсорбционной активности по йоду и фенолу отклоняются в точке $\mathrm{R}_{\mathrm{KOH}}=0.5 \Gamma / г$, что может быть связано с эффективной сорбцией в микропорах для данного углеродного сорбента.

Получение сорбентов из бурого угля при $\mathrm{R}_{\mathrm{KOH}}$ $=1 \Gamma / \Gamma$ приводит к увеличению характеристик пористости сорбента и увеличению сорбции по метиленовому голубому. При этом соотношении наблюдается максимальный объём мезопор. Однако, прирост основных характеристик не столь значителен, как при использовании массового соотношения $\mathrm{R}_{\mathrm{KOH}}=0.5 \Gamma / \Gamma$.

Отдельное место занимают сорбенты, полученные при $\mathrm{R}_{\mathrm{KOH}}=2 \Gamma / \Gamma$. С одной стороны использование большого количества щёлочи при активации повышает значения всех текстурных и адсорбционных характеристик (наибольший прирост наблюдается для сорбции йода из водного раствора), с другой стороны большое количество щёлочи усложняет процесс очистки готового сорбента. 


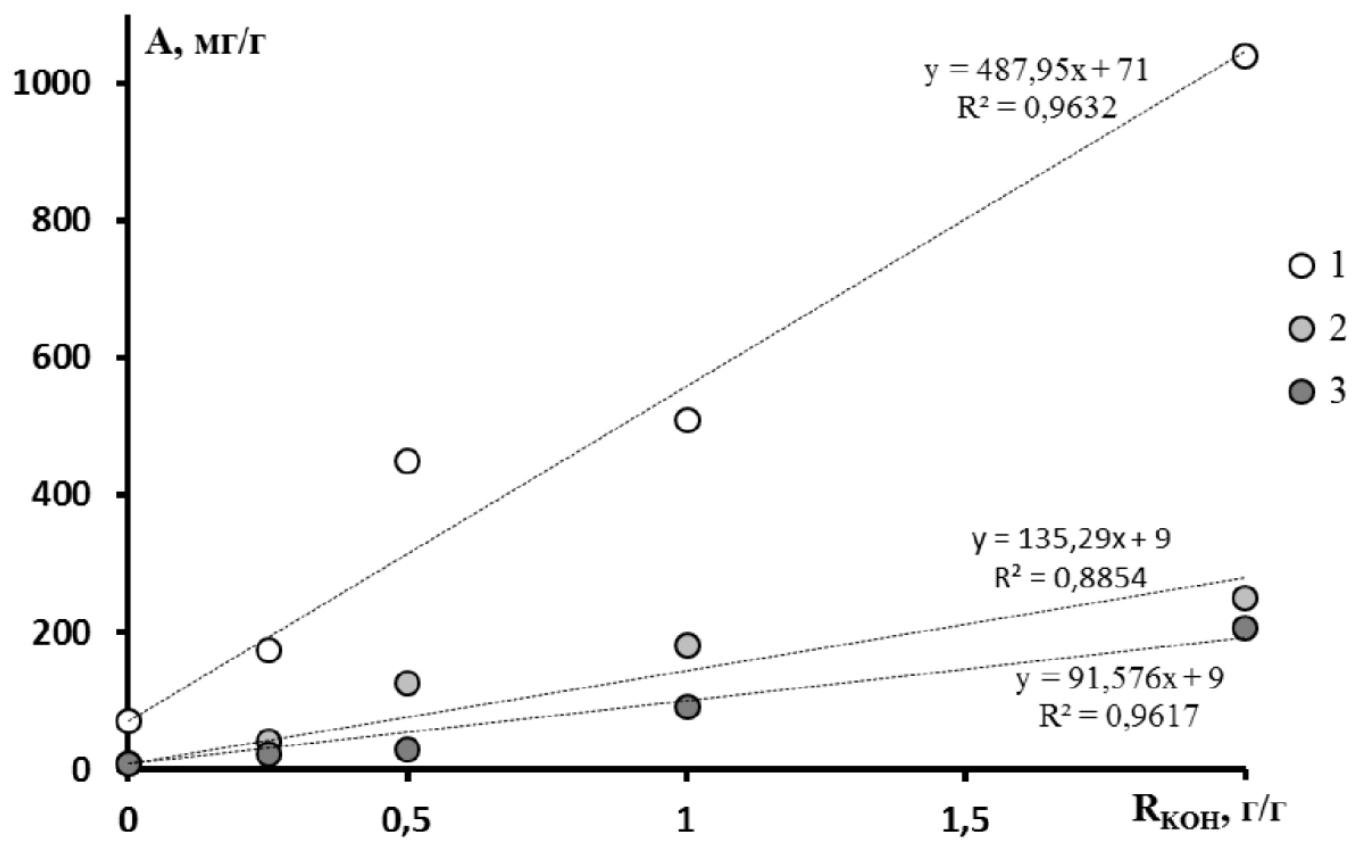

Рис. 3. Зависимости адсорбционных активностей (A, мг/2) от массового соотношениях КОН/уголь

$\left(R_{\text {Кон }}\right)$ по отношению к водным растворам йода (1), фенола (2) и метиленового голубого (3) для сорбентов, полученных из угля Тисульского месторождения

Fig. 3. Dependence of adsorption activities $(A, \mathrm{mg} / \mathrm{g})$ on $\mathrm{KOH} / \mathrm{coal}$ mass ratios $\left(R_{\mathrm{KOH}}\right)$ with respect to aqueous solutions of iodine (1), phenol (2) and methylene blue (3) for sorbents obtained from the coal of the Tisulskoye field

Использование большого количества щёлочи остаётся целесообразным для получения сорбентов с наиболее высокими характеристиками, однако, наибольшее практическое значение всё-таки имеет использование массового соотношения КОН/уголь не более $1 \Gamma / \Gamma$.

\section{Выводы:}

Методом щелочной активации получены сорбенты на основе бурого угля Тисульского месторождения. Углеродные сорбенты получены при различном соотношении КОН/уголь $\left(\mathrm{R}_{\mathrm{KOH}}\right)-$ $0.25 г / \Gamma ; 0.5$ г/г; 1 г/г и 2 г/г. Показано положительное влияние количества гидроксида калия, вводимого в уголь на стадии пропитки, на характеристики сорбентов, получившихся после щелочной активации. C ростом $\mathrm{R}_{0}$ сорбция йода, фенола и метиленового голубого возрастает вследствие развития пористой структуры сорбента. Для всех полученных сорбентов характерно преобладание микропор в пористой структуре. Наибольший прирост текстурных и сорбционных характеристик наблюдается при использовании соотношения КОН/уголь 0.5 г/г.

Работа выполнена в рамках государственного задания (проект АААА-А17-117041910147-2).

Работа выполнена с использованием оборудования ЦКП ФИЦ УУХ СО РАН.

\section{СПИСОК ЛИТЕРАТУРЫ}

1. Гостищев Д.П., Хуторова А.О., Широкова В.А. Экологические проблемы охраны водных ресурсов от загрязнения сточными водами и животноводческими стоками // Природообустройство. 2013. №3. С. 1824.

2. Берлинтейгер Е.С. Изучение основных видов загрязнений водных ресурсов Кузбасса // Международный журнал прикладных и фундаментальных исследований. 2013. №11-1. С. 55.

3. Wang Guofa, Xu Yongxiang, Ren Huaiwei. Intelligent and ecological coal mining as well as clean utilization technology in China: Review and prospects // International Journal of Mining Science and Technology. 2018. V. 9. P. 54-62. 
4. N.B. Singha, Garima Nagpalb, Sonal Agrawala, Rachnaa Water purification by using Adsorbents: A Review // Environmental Technology \& Innovation. 2018. V. 11. P. 187-240.

5. Imran Ali, Mohd. Asim, Tabrez A.Khan. Low cost adsorbents for the removal of organic pollutants from wastewater // Journal of Environmental Management. 2012. V. 113. P. 170-183.

6. Sabino De Gisi, Giusy Lofrano, Mariangela Grassi, Michele Notarnicola / Characteristics and adsorption capacities of low-cost sorbents for wastewater treatment: A review // Sustainable Materials and Technologies. 2016. V. 9. P. 10-40

7. Geoffrey S. Simatea, Nthabiseng Maledia, Aoyi Ochiengc, Sehliselo Ndlovua, Jun Zhangd, Lubinda F. Walubitae. Coal-based adsorbents for water and wastewater treatment. // Journal of Environmental Chemical Engineering. 2016. V. 4. Issue 2. P. 2291-2312.

8. Передерий М.А. Сорбционные материалы на основе ископаемых углей // Химия твёрдого топлива. 2000. №1. С. 35-44.

9. Зыков И.Ю., Дудникова Ю.Н., Козлов А.П., Федорова Н.И., Исмагилов 3.Р. Адсорбционные характеристики углеродных сорбентов из природноокисленного барзасского угля // Химия в интересах устойчивого развития. 2017. Т. 25. № 6. С. 621-625.

10. Fedorova N.I., Manina T.S., Ismagilov Z.R. Effect of the mechanoactivation treatment of coals mixed with an alkali on the properties of adsorbents obtained on their basis // Solid Fuel Chemistry. 2014. V. 48. № 4. P. 245-250.

11. Marsh H. Formation of active carbons from cokes using potassium hydroxide / Marsh H., Yan S. Denis // Carbon. 1984. V. 22. N. 26. P. 603-611.

12. Lillo-Rodenas M.A. Understanding chemical reactions between carbons and $\mathrm{NaOH}$ and $\mathrm{KOH}$. An insight into the chemical activation mechanism / M.A. Lillo-Rodenas, D. Cazorla-Amoros, A. Linares-Solano // Carbon. 2003. V. 41. № 2. P. 267-275.

13. Miluše Jochová, Miroslav Punčochář, Jan Horáček, Karel Štamberg, DušanVopálka. Removal of heavy metals from water by lignite-based sorbents // Fuel. 2004. V. 83. Issue 9. P. 1197-1203.

14. Yurong Dong, Xiurong Ren, Meijun Wang, Qiang He, Liping Chang, WeirenBao. Effect of impregnation methods on sorbents made from lignite for desulfurization at middle temperature // Journal of Energy Chemistry. 2013. V. 22. Issue 5. P. 783-789.

15. Козлов А.П., Дудникова Ю.Н., Зыков И.Ю., Созинов С.А., Исмагилов З.Р. Методические аспекты определения параметров пористой структуры углеродных сорбентов на основе ископаемых углей // Вестник Кузбасского государственного технического университета. 2017. № 6 (124). С. 197-204.

\section{REFERENCES}

1. Gostishhev D.P., Xutorova A.O., Shirokova V.A. Environmental problems of protection of water resources from pollution by wastewater and livestock runoff // Prirodoobustrojstvo.2013. V. 3. P. 18-24. (in Rus)

2. Berlintejger E.S. Study of the main types of pollution of water resources of Kuzbass // Mezhdunarodnyj zhurnal prikladnyx i fundamentalnyx issledovanij. 2013. V.11-1. P. 55. (in Rus)

3. Wang Guofa, Xu Yongxiang, Ren Huaiwei. Intelligent and ecological coal mining as well as clean utilization technology in China: Review and prospects // International Journal of Mining Science and Technology. 2018. V. 9. P. 54-62.

4. N.B. Singha, Garima Nagpalb, Sonal Agrawala, Rachnaa Water purification by using Adsorbents: A Review // Environmental Technology \& Innovation. 2018. V. 11. P. 187-240.

5. Imran Ali, Mohd. Asim, Tabrez A.Khan. Low cost adsorbents for the removal of organic pollutants from wastewater // Journal of Environmental Management. 2012. V. 113. P. 170-183.

6. Sabino De Gisi, Giusy Lofrano, Mariangela Grassi, Michele Notarnicola / Characteristics and adsorption capacities of low-cost sorbents for wastewater treatment: A review // Sustainable Materials and Technologies. 2016. V. 9. P. 10-40.

7. Geoffrey S. Simatea, Nthabiseng Maledia, Aoyi Ochiengc, Sehliselo Ndlovua, Jun Zhangd, Lubinda F. Walubitae. Coal-based adsorbents for water and wastewater treatment. // Journal of Environmental Chemical Engineering. 2016. V. 4. Issue 2. P. 2291-2312.

8. Perederiy M.A. Sorption materials on the base of coals // Solid Fuel Chemistry. 2000. №1. P. 35-44.

9. Zykov I.Yu., Dudnikova Yu.N., Kozlov A.P., Fedorova N.I., Ismagilov Z.R. Adsorbtsionnye kharakteristiki uglerodnykh sorbentov iz prirodnookislennogo barzasskogo uglya // Chemistry for Sustainable Development. 2017. V. 25. № 6. P. 621-625. (in Rus)

10.Fedorova N.I., Manina T.S., Ismagilov Z.R. Effect of the mechanoactivation treatment of coals mixed with an alkali on the properties of adsorbents obtained on their basis // Solid Fuel Chemistry. 2014. V. 48. № 4. P. 245-250. 
11. Marsh H. Formation of active carbons from cokes using potassium hydroxide / H. Marsh., Denis S. Yan // Carbon. 1984. V. 22. № 26. P. 603-611.

12.Lillo-Rodenas M.A., Cazorla-Amoros D., Linares-Solano A. Understanding chemical reactions between carbons and $\mathrm{NaOH}$ and $\mathrm{KOH}$. An insight into the chemical activation mechanism// Carbon. 2003. V. 41. № 2. P. 267-275.

13.Miluše Jochová, Miroslav Punčochář, Jan Horáček, Karel Štamberg, DušanVopálka. Removal of heavy metals from water by lignite-based sorbents // Fuel. 2004. V. 83. Issue 9. P. 1197-1203.

14.Yurong Dong, Xiurong Ren, Meijun Wang, Qiang He, Liping Chang, WeirenBao. Effect of impregnation methods on sorbents made from lignite for desulfurization at middle temperature // Journal of Energy Chemistry. 2013. V. 22. Issue 5. P. 783-789.

15.Kozlov A.P., Zykov I.Yu., Dudnikova Yu.N., Sozinov S.A., Ismagilov Z.R. Metodicheskie aspekty opredeleniya parametrov poristoy struktury uglerodnykh sorbentov na osnove iskopaemykh ugley // Vestnik Kuzbasskogo gosudarstvennogo tekhnicheskogo universiteta. 2017. № 6 (124). P. 197-204. (in Rus) 